\title{
Conversation analysis and telephone helplines for health and illness: A narrative review
}

For publication in Research in Social Language and Interaction Special Issue

Steven Bloch, University College London, UK

Geraldine Leydon, University of Southampton, UK

\begin{abstract}
What do we know about how telephone helplines support, inform and advise people with a range of physical and mental health concerns? Conversation Analysis has over the recent decade provided a wealth of analytic insight into how call-takers and callers bring off what are sometime very sensitive and challenging encounters. We review 37 studies offering finegrained analysis of audio-recorded naturally-occurring helpline interactions. We describe the main practices identified including openings and trouble-tellings, emotions and responses, advice giving, closings, authenticity, identity and assessments. We conclude with consideration of how the study of helplines might evolve, including the comparison of telephone-based support with that provided via other technologies such as on-line chat. Data are in British English.
\end{abstract}




\section{Helplines: Overview and Background}

This review focuses on published work that examines interactions in health/illness related telephone helplines, established to help callers with physical and mental health enquiries (not emergency calls) across the life-course. In 2019 there were an estimated 2500 helplines in operation in the $\mathrm{UK}^{1}$ with many offering services pertaining to various forms of health and illness including cancer, end of life, neurological conditions, heart disease and mental health. Services are often provided through third sector (non-Governmental) organisations such as charities. Callers may be making contact on their own behalf or with issues relating to a family member or friend. The call taker may be a health or social care trained professional (e.g. a nurse) with some specialist knowledge and/or experience of the issues likely to arise in the call. What they all have in common is a basic institutional framework featuring a caller who is seeking some form of advice, help or support (however defined) from a call-taker. The use of such helplines across the sector can only be estimated but figures from individual services indicate that the volume of call is large. Kids Helpline in Australia for example received in excess of one million calls a year (Danby, Baker, \& Emmison, 2005), with medical charity helplines such The UK Macmillan Cancer Support helpline receiving over 140,000 calls in 2014.

Such helplines vary considerably in their remit and the services they offer but typically they aim to address a specific area of health, illness and/or wellbeing. Despite having a dedicated remit, such as a service for people with one particular medical diagnosis, the range of potential issues with which callers may present is vast. These can include practical requests of how to negotiate complex health services or obtain vital health care equipment to support self-management, help with financial and insurance matters, information requests to enhance understanding of a particular illness or treatment regime and, relatedly, emotional or psychosocial support needs to help cope with health problems, including issues around the management of long term co-morbid conditions. A single call may demand discussion of just one problem that sits neatly in one of these domains, while many will require participants to discuss concerns that are cross cutting.

Helplines themselves defy easy definition. The UK Helplines Partnership refers to support for organisations 'involved in providing multi-channel support to the public or a specific sector with the aim of improving an individual's wellbeing'. A more precise definition relates to services offering 'callers help, advice or support in a wide range of areas, most commonly in areas relating to health and medicine..' (p.1) (Firth, Emmison, \& Baker, 2005).

Professional bodies themselves recognise the importance of helplines and do provide a certain degree of guidance for practitioners: The UK Royal College of Nursing (2006) for example sets out guidelines for practitioners working on telephone helplines for people with long-term conditions. It states that a call should include mutual agreement between the calloperator and the caller regarding (a) what the problem is and (b) what help or advice the caller is seeking. Although such guidelines are certainly useful to some degree, they are far from comprehensive.

Typically helpline calls are characterised by a caller seeking some sort of help, whether in the form of information, support or advice, from a formally recognised organisation permitted to offer a specialist telephone advice service. Call takers will usually

' Personal communication with Head of Membership at the Helplines Partnership, 04/02/19 
be trained and have expert knowledge and/or experience in a particular area, in order to facilitate the provision of help in the form of information, support and for some helplines, advice (we will return to this point later). In terms of the service modality, clearly the core business of (most) helpline services is to provide help through voice alone via the telephone, with no visual cues and no potential for physical examination of the caller's complaint. In this context, one of the potential challenges for callers, and call takers, is to establish not just what type of help is being requested but also what can be legitimately sought and provided; articulating and managing expectations can become an important task for participants. Looking at helpline calls through the lens of the 'phased structure' or architecture of other health care encounters that have been extensively analysed and documented in the CA literature (Robinson, 2003) helps us further outline the particular work of the helpline. As one may expect, the phased structure of helpline calls echoes some of the features or activities commonly found in other encounters e.g. family practice/GP consultations, but there are obvious departures. In terms of similarities, in the simplest of terms, most calls as with most (face-to-face) healthcare consultations, provide an opportunity for the help-seeker to present their reason for the call or chief concern and this typically occurs during the opening phase. Next, call-takers then use the problem presentation to enable forward movement to the next phase in which they seek to elicit further details of the problem (akin to history taking in the primary and secondary care consultation). This then typically skips the physical examination and segues to the next phase of making some sort of recommending action to help manage / resolve the problem. With no visual access to callers, including when callers exhibit some signs of distress (e.g. tears), may make it hard for the call taker to judge what might be an appropriate next turn (Hepburn and Potter, 2007).

Hence, we can see from even a zoomed-out description of helpline work there is a significant departure from many 'typical' consultations. In primary care, clinicians are at liberty to examine a patient when face-to-face and inspect prior medical records whether face-to-face or not, both of these activities can serve to enhance practitioner epistemic access to the problem in hand and, vitally, can provide the evidential basis for their recommendation, and make these transparent to patients. The types of recommendation calltakers can make are, by comparison, constrained and limited with diagnosis and treatment recommendations firmly 'off the menu'. Rather, their actions typically involve signposting to other services (e.g. GP), offering information (e.g. leaflets, website materials) and just being a 'listening ear', often translated as 'offering emotional support' (but most will stop short of counselling/therapy services). Helpline help is, in this sense, rather different from other types of encounter and the organisation of such services is complex. This invites us to ask how do participants themselves orientate to the opportunities and constraints of helpline services?. From even a cursory view of the literature it is clear that the mission and remit of helpline services can vary enormously (Hopper, 1993) and offers unique challenges for parties to the talk.

\section{Why do we need this review?}

The motivation for this review is both intellectual and practical. As with many areas of everyday life, what goes on between two people on a health helpline remains largely unknown. Thus, whilst the evidence base continues to grow there is an intellectual need to consider how, precisely, helpline talk is accomplished and how relationships can be located (Hepburn, 2005). Practically, there is an on-going interest in understanding how organisations can optimise their services for callers, many of whom may be vulnerable or distressed (Kitzinger, 2011). These two primary drivers to reviewing the state of the literature 
are nested in a broader service delivery context of increased telephone based consultations and rising use of helpline services. Remote consulting and telephone-based help services are unlikely to replace face-to-face consultations or counselling, but for practical reasons of time and cost it is without doubt a feature of current health systems and will increasingly be so in the future. There is also a conceptual shift in health care responsibility with an increase in self-reliance and the expert patient, particularly for longer term conditions (Taylor \& Bury, 2007). Such a shift is reflected in the use of new technologies designed to empower service users.

Given the current trend of online support, rather than voice-to-voice telephone interaction there may be a case for seeing telephone helplines as less relevant. However, a case can be made for helplines remaining critical for people with complex, underspecified problems. A relatively simple fact-based problem may be more easily resolved via online guides but people using helplines may be calling for reasons as said unknown or ones that are difficult to articulate (in terms of complexity and/or emotion).

\section{In the beginning... where Conversation Analysis started}

Telephone mediated help was central to the pioneering work of Harvey Sacks and the establishment of Conversation Analysis. In 1964, Sacks collected data from a suicideprevention helpline based in a psychiatric hospital. This work also formed his first publication on the search for help (Sacks, 1967). As described by Schegloff in his introduction (Sacks, 1992, Vol 1) in 1963-64 Sacks, and Garfinkel, served as Fellows at the Center for the Scientific Study of Suicide in Los Angeles. During this time Sacks came across stenographic transcripts, and then the tapes of the telephone calls to the Suicidal Prevention Centre of, or about, suicidal persons. Late in 1964 Sacks and Schegloff discussed a recurrent and much discussed practical problem faced by those who answered phone calls to the Suicidal Prevention Centre by suicidal persons or about them - the problem of getting the callers to give their names - i.e. a practical, institutional problem. Whilst much of the pioneering analysis developed with reference to mundane everyday talk, institutional talk has been a central concern of CA for nearly 50 years (Drew \& Heritage, 1992).

\section{Methodology}

In searching and reviewing the literature for this paper we have adopted a scoping/narrative approach rather than a more formal systematic review process. We have also been informed by a conversation analytic specific guide to reviewing the literature (Parry \& Land, 2013).

\section{Literature search}

To identify relevant published literature we searched a number of relevant electronic data bases: Linguistics \& Language Behaviour Abstracts (LLBA), PsycInfo, Scopus, Web of Science, Medline and CINAHL Plus. The search terms addressed methodology (conversation analysis), setting (helplines, telephone counselling) and topic (physical and mental-health, wellbeing and illness). The search was filtered for literature published in English dating from 1960 onwards. The initial search targeted Journal publications but a hand-search snowballing technique was then used to locate relevant book chapters. This involved a review of reference lists in key articles and also a search of relevant authors' bibliographies.

\section{Selection}


Our selection process involved a review of abstracts and full texts where appropriate. Studies for inclusion were those presenting data in British English, based on fine-grained analysis of audio recorded naturalistic helpline interactions; that address physical or mental health, illness or wellbeing where the telephone helpline service is designed to provide some form of help, advice, counselling or guidance. This excluded calls to emergency services (a call for immediate assistance and/or dispatch of a service) and calls to access a medical practitioner (e.g. calls to a primary physician receptionist).

\section{Synthesis}

Once the collection of papers and chapters had been made we extracted basic information relating to the type of helpline service, the classification of call taker (e.g. professional or peer), and caller (child/adult). We also considered the objectives of the work with reference to future practical applicability. Our main focus was on the practices examined in the analysis. These were listed with reference to the authors' analytical claims and then grouped into seven main areas: openings and problem presentations, emotions, advice sequences, identity, authenticity, assessments, and closings. Two additional points can be made about these themes. The first is that they are not all mutually exclusive. Thus whilst the sequential organisation of openings and closings are clearly boundaried, the notion of identity, for example, is not restricted to a structural location. Secondly, these themes address the main areas we have identified. We do not claim, nor have we attempted, to review every analytical point made but rather to provide a reasonable coverage of what has been said about interactions on medical helplines and what this tells us about the state of the art with reference to helplines, medical interactions and the wider field of CA itself. We also have not conducted a formal quality appraisal but do comment on the type and amount of data and the depth of analysis where appropriate.

There are two significant collections examining helplines from an interactional perspective. 'Calling for Help' (Baker, Emmison, \& Firth, 2005) presents an international perspective featuring calls across a wide range of helpline services, a number of which we discuss later. In their introduction to this text Firth et al. note a number of common features across the helplines including 'the participants joint orientation to the overarching interactional goal of seeking and providing help' (p.2) and to the role and responsibility separation between caller and call taker. The latter invokes the intractable institutionality of these encounters.

This text was followed by a special edition of Research on Language and Social Interaction (Edwards, 2007). This issue presented five papers spanning a variety of helplines but all featuring calls for help but varying in terms of the nature of the problem (acute or long (term), reasons for calling, and the ways in which calls for help are presented and actioned.

\section{Key argument}

Helplines afford specific opportunities for the exploration and potential remediation of caller problem presentations but there are unique challenges, some of which have been raised in brief above. What may appear prima facie to replicate the well-recognised phased structure of the primary care consultation (Maynard \& Heritage, 2005) typically turns out to be somewhat different both in terms of physical distance, or the remote nature of the interaction, and the 
accomplishment of key tasks (such a responding to a diagnosis request or a call for emotional support).

It is also the case that the apparent simple job of presentation a problem is, in reality, anything but straightforward. Callers may not be able to easily formulate their reason for calling, nor may it be easy to design their concern(s) to meet the institutional demands of the helpline. Equally, how participants accomplish the telling and receipt of troubles may be challenging. There is also the issue of help and advice. How these play-out in interaction may well depend on specific institutional boundaries and expectation of empowerment.

\section{The current state of the art}

The past 20 years have seen an ongoing interest in, and study of, talk on health-related helplines. The service range of original research includes: adult community mental health (Pudlinksi, 2002) cancer (Leydon, Ekberg, \& Drew, 2013; Woods, Drew, \& Leydon, 2015), child physical and mental health (Butler, Danby, Emmison, \& Thorpe, 2009; Hepburn \& Potter, 2007), alcohol, drugs and poisons

(Landqvist, 2005; Stommel \& Molder, 2018), acquired neurological conditions (Bloch \& Antaki, 2018) and women's health and childbirth (Shaw \& Kitzinger, 2013).

We have identified 37 papers and book chapters that fit our criteria for physical or mental health-related helpline research using clear conversation analytic principles, excluding papers that deal with emergency calls for help (e.g. ambulance services) or those seeking direct access to primary health services (such as NHS Direct). We have included two papers that incorporate analysis of text based support services (email or synchronous online chat) but only where they are accompanied by telephone helpline data and analysis (Harris, Danby, Butler, \& Emmison, 2012; Stommel \& te Molder, 2015).

The balance across published papers is approximately two-thirds adult oriented services and one-third child services. The majority present collections of data fragments across a number of calls to one named helpline, with four utilising data from a single call (Butler, Danby, \& Emmison, 2015; Kitzinger \& Rickford, 2007; Shaw \& Kitzinger, 2013; Te Molder, 2005). Two publications directly address the application of CA to service development, including a critical perspective on how CA can be used as part of a process of change (Hepburn, Wilkinson, \& Butler, 2014; Kitzinger, 2011).

One key distinction between health helplines is in terms of core activity - it may well be that all helplines are there to provide support and information - but by the nature of the problems they address some are far more specific in what they are attempting to do. Counselling based services are there to listen and support, the more physical health-based lines offer a degree of support and listening but are more aligned to a medical approach of problem presentation and attempts to provide information to enable some form of resolution of the presenting enquiry. Leanqvist (2005) for example discusses the estimation of risk in calls to the Swedish Poison Information Centre in which the pharmacist routinely categorizes calls according to the estimated risk of the incident (clear risk, some risk or no/ small risk). In such circumstances the task at hand is evidently more prescribed and immediate when compared with other kinds of helpline activity. Equally, a peer run community mental health helpline (or 'warmline'), for example, is different in terms of institutional role, objectives, and expectations when compared to, for example, a child protection helpline. As a result call takers vary across the sample of papers included in the review; counsellors (as a generic category of call helper) make up the majority with nurses and then peers/volunteers. 
For the majority of helplines it is the caller, not the call-taker, who has to clearly specify the need and, sometimes, signal the action response that is required e.g. a listening ear, information or an advice request. This distinguishes helpline calls reviewed here from emergency service help calls (fire, police, ambulance) in which the call taker is mandated to respond with, or at least to establish the need for, an expected action. This distinction is, however blurred somewhat by services which may have a dual role - e.g. a listening role as well as one with legal responsibility to act in situations of reported harm or abuse such as child protection issues.

A few papers consider the technologies employed by organisations to make possible the delivery of advice, help and support, drawing attention to the distinct properties of nonface-to-face interactions. Harris, Danby, Butler, \& Emmison (2012), for example, examine the interface between telephone and email help services. Their work explores how counsellors on the Kids Helpline use emails to propose a shift from asynchronous email counselling to telephone counselling or synchronous online chat. They show how counsellors 'build a case' for the proposed modality shift and how requests are produced indirectly to enable callers the opportunity to decline the proposed shift, without threatening an existing established relationship. Stommell and te Molder (2015) present an analysis of closings across two media: telephone calls and online text based synchronous chat sessions. For the telephone conversations a normative practice of closing initiation by the caller is evidenced. In contrast, whilst caller initiated closings are also displayed in chat sessions, a number of chat closings lacked an advice acknowledgement that was sufficient to work as a pre-closing. The authors suggest that this may, in part, account for why call takers report that online chat is a less satisfying experience than telephone talk but that equally, callers can more easily resist advice via chat and thus may consider chat as more attractive. We return to the theme of 'advice' by call takers in the next section where we outline key practices identified and described in the included literature.

\section{Main helpline practices}

\section{Openings and trouble tellings}

Establishing the reason for a telephone call has been a central concern within CA enquiry since its early beginnings (Schegloff, 1979, 1986, 1968). Openings in non-institutional calls have been shown to operate through a set of fundamental sequences including summons and answer, identification and recognition, and the 'howareyou' sequence (Schegloff, 1986). These sequences provide an environment in which the reason for calling can be established. The openings to institutional telephone calls differ in a number of ways (Whalen \& Zimmerman, 1987).

One institutional feature common to a number of helpline services is that callers may speak to a 'front line' call-taker prior to receiving the desired help or advice. A front-line operator, may be required to direct callers to the most appropriate specialist. Larger disease specific helplines for example will often triage calls depending on the type of advice sought (disease specific, social support, finance etc.). One such study deals with the opening stages of telephone calls to a cancer helpline in which calls are triaged to a specialist nurse as call taker from front-line helpline call-handlers (Leydon et al., 2013). This triage involves the collection of basic information which is passed onto the nurse prior to the caller and nurse's conversation. The information, and how it is managed by the nurse in the opening sequence of talk is shown to require delicate management to avoid disruption to call progressivity. The nurse has information about the caller (including their name) but the caller lacks knowledge 
of what the nurse has been told. The authors identify potential for a collision between the normative procedures for openings (Schegloff, 1986) and the organisation of helpline interactions. Progressivity was clearly enhanced in calls using a brief four part turn comprising including Recognition of the patient ("Hello Mrs Smith..."), self Identification (e.g. "I'm Kelly one of the nurses"), Formulation of the callers problem ("I understand you are calling about...is that right") and a Request for further telling ("how can I help today"/"would you like to tell me more") (RIFR). See fragment 1 for an example of the fourpart opening.

\section{Extract 1: Opening}

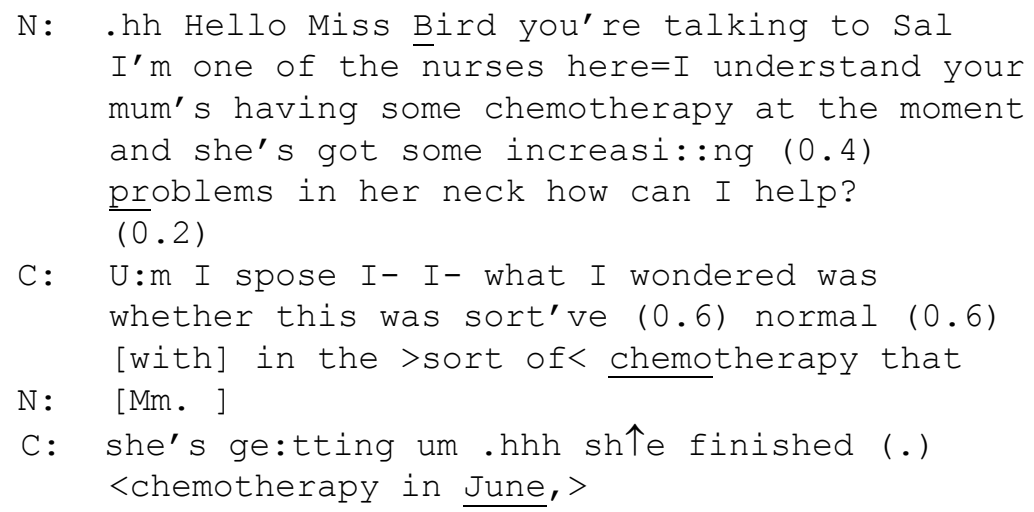

[Source: Leydon et al., 2013]

The authors concluded that when all four parts were not present progression to the nurse call was hindered. They conclude "the smooth exchange of information and provision of support in a trusted call environment is a critical goal of any helpline; a fluid call opening in a triage environment may significantly optimise the possibility of this goal being realized" (ibid, p28). In contrast, with reference to establishing the reason for the call, Danby, Baker and Emmison (2005) offer a number of observations on openings to Kids Help Line. The first is that the greeting turn used in the call-taker's first turn 'in which only an organisational identification is provided, serves to purpose - although not ensure - that the caller, should they choose, can remain anonymous.' (p133).

Extracts 2 \& 3: Openings

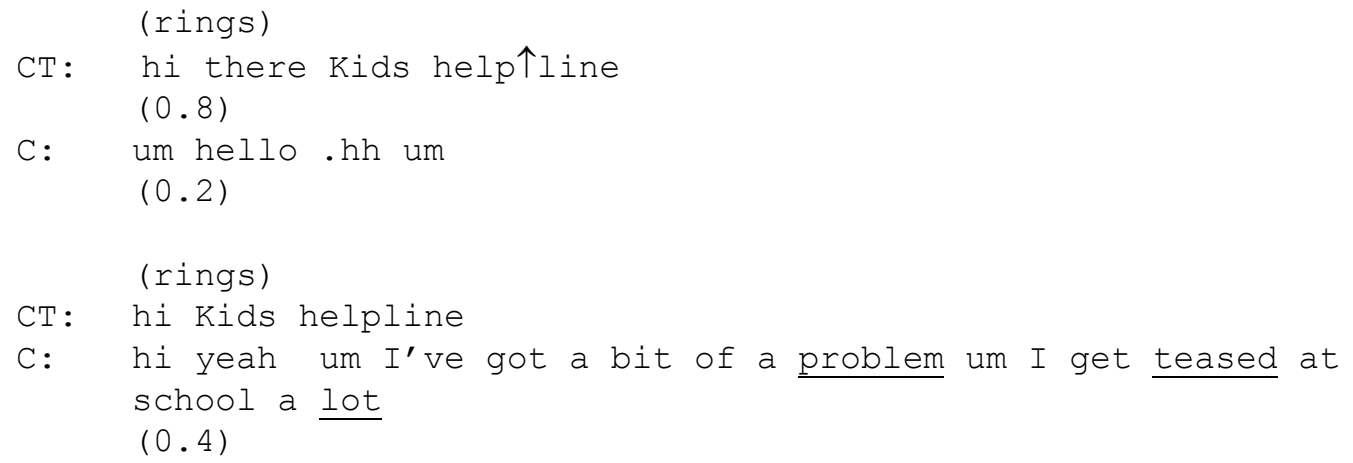

[Source: Danby et al., 2005] 
Call-takers answer the call summons with ' $h i$ there Kids Helpline' with no further personal identification, thus avoiding giving callers an implied obligation to provide their names. This is a feature specific to helplines and other non-face-to-face services - the opportunity for anonymity (hence Sacks' (1967) original issue re: caller identification to a suicide prevention service). Further, the authors make an important distinction between reason for the call and the problem. For example, the problem might be 'being kicked out of home', but the reason for the call is 'not knowing what to do'. The counsellors may well be listening for the reason for the call rather than the problem. This work suggests that it is unwise to assume the 'reason' for calling is obvious. Indeed, the reason may not be entirely clear to the person making the call, which has clear implications for the likely clarity of the reason for the call handler.

In their study of calls to National Society for the Prevention of Cruelty to Children Helpline (NSPCC) Potter \& Hepburn (2003) examine caller concern constructions - how these are used early in the call to display a stance of the caller and as an integral part of the caller's reason for the call. Such constructions are shown to be oriented to a pre-move in the caller's reason for call and to project the unpacking of concerns in a way that is oriented to the NSPCC's institutional role.

\section{Extract 4: Caller constructions}

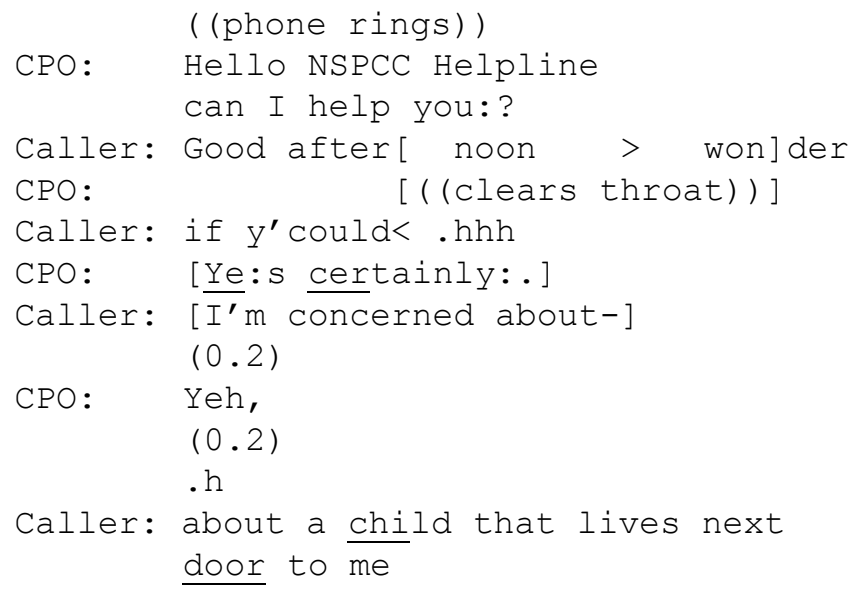

[Source: Potter and Hepburn, 2003, p204]

Such work reveals the delicacy of such presentations, particularly the way in which call takers will use a concern construction early in the call even if the caller does not, thus enabling the caller to formulate their reason for calling as a concern that can then be explored. This work points to the ways in which a caller's reason for making contact may not be obvious. In discussing a caller's opening 'I just want to hear somebody right now' te Molder (2005) examines how this turn is treated by the call taker (a counsellor) as an indirect request for help. The call taker reformulates the caller's presentation, showing how the caller's apparently obvious reason for making contact is not taken for granted or fixed (see also 'identity' below).

As well as managing how a problem is expressed as a problem or concern there has been consideration of how a problem is presented in order for it to be addressed. Shaw \& Kitzinger (2013), for example, consider the organisation of problem presentation to a home birth helpline, noting how the call taker is careful not to bring the problem presentation to 'premature termination' (which might cut off important future material) or to premature 
judgment. Additionally, Bloch \& Antaki, (2018) consider the impact of a problem presentation on the caller and subsequent uptake of the problem by the call taker. They explored how callers and call takers arrive at a point whereby there is a shared agreement that the problem has been stated. In their study of calls to specialist nurses on a Parkinson's disease helpline they examine so called 'exit devices' (Robinson \& Heritage, 2005) enabling participants to move from an account of their issues to whatever might follow. Of note is the examination of how the call-takers uptake the problem. They show how, in many cases, the call-taker highlights or attends to the physicality of the problem rather than, for example, its emotional impact. This may ground the problem in terms the nurse (as call-taker) can then address (so called nurseability of the problem). In extract 5, the caller has just presented his problem in terms of coping with his wife's diagnosis of Parkinson's disease together with depression. The nurse's uptake is clearly grounded in physical symptoms rather than responding substantially to the caller's ability to cope.

Extract 5: Problem presentations and receipts

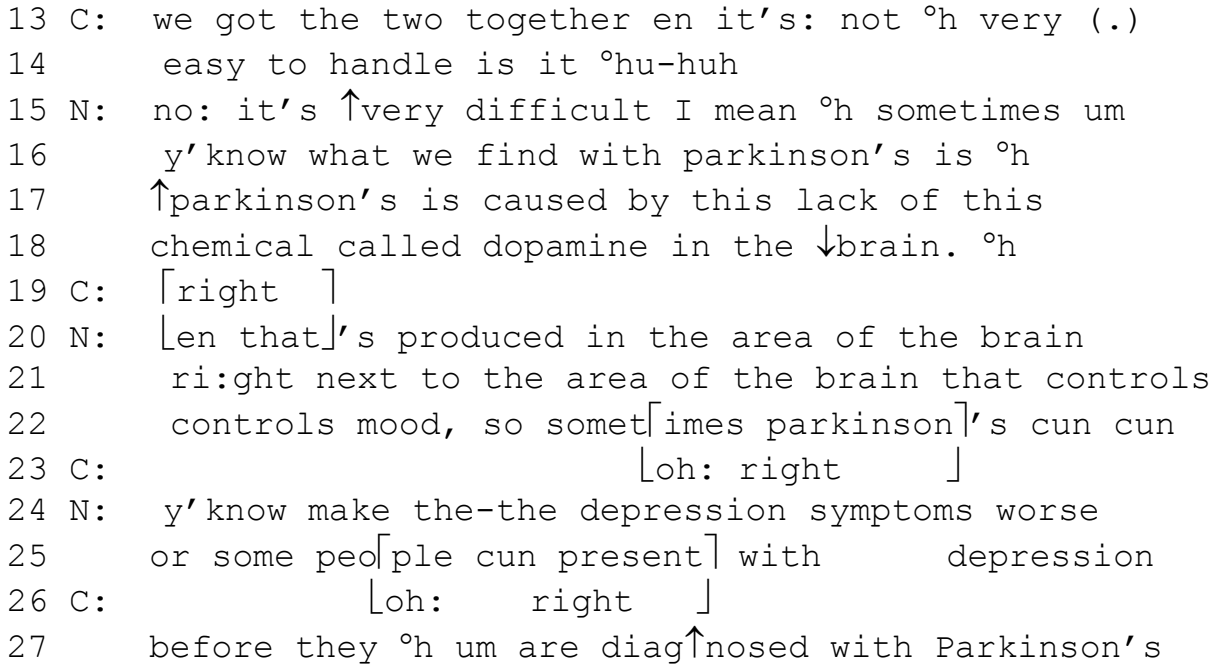

[Source: Bloch and Antaki, 2018,p7]

This has relevance to the helpline context insofar as the nurse has certain boundaries that restrict opportunities for medical problem resolution. The call-taker can listen, explain and signpost to other services but cannot offer direct physical or medial intervention.

\section{Emotions and responses}

A second clear theme identified in this review concerns caller emotions and call-taker responses to trouble-tellings. We note that that the emotions are typically ones of distress or panic, driven by the circumstances leading to the caller seeking help (e.g. child abuse, birthing complications etc.). This presents a potential institutional dilemma for the call taker: responding to the distress and, at the same time, taking whatever actions might be necessary as part of their institutional role or aim (supporting self-management, evidence gathering, information sharing etc.). The main focus of the emotion related work reviewed here has been empathy, which has already been found to be used in institutional interactions for performing institutional tasks, such as terminating a troubles-telling sequence (Ruusuvuori, 2007). 
In an analysis of calls to a pre-crisis community mental health peer support helpline Pudlinski (2005) reveals eight different ways of expressing empathy and/or sympathy in response to a caller's trouble telling, ranging from emotive reactions to sharing a similar experience or similar feelings. It is also shown how empathy and sympathy are expressed at various places within a troubles-telling.

In their analysis of calls to a child protection helpline Hepburn and Potter (2007) focus on two types of crying receipts by call-takers: so called 'take your times' and emphatic receipts, such as 'Oh my gosh'.

Extract 6: Take your time

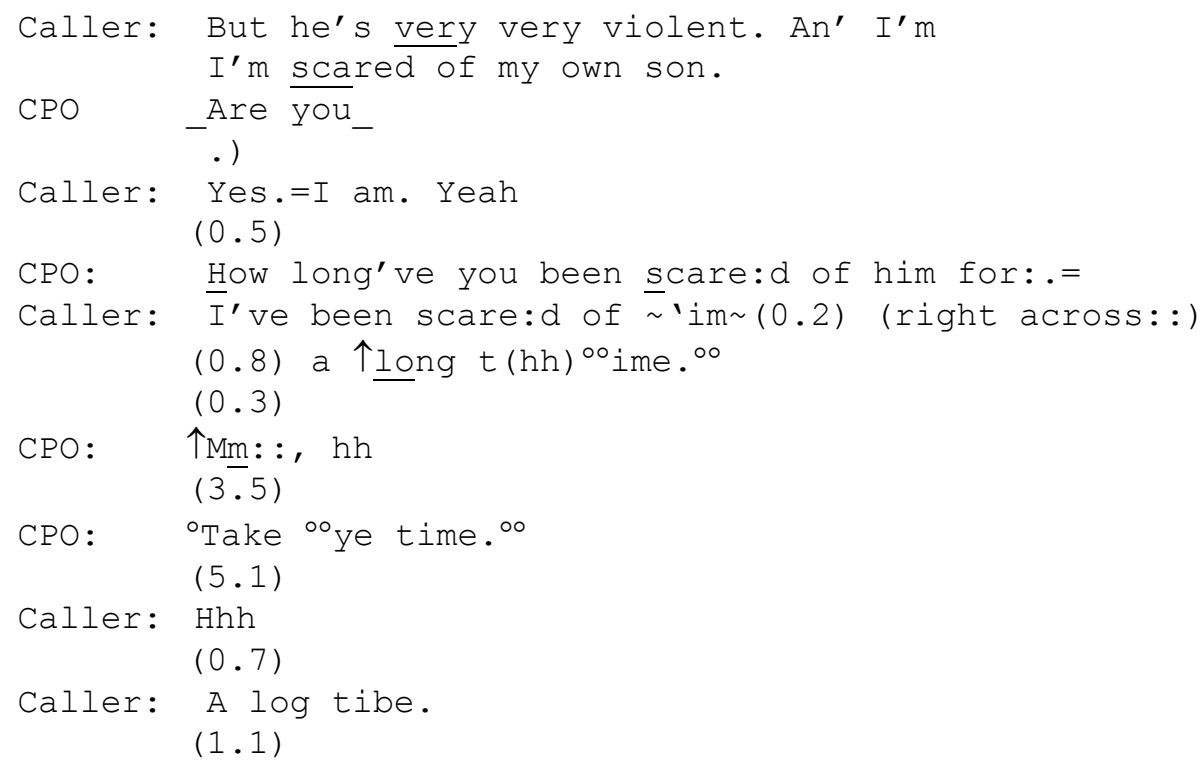

[Source: Hepburn \& Potter, 2007: p93]

Extract 7: Emphatic receipts

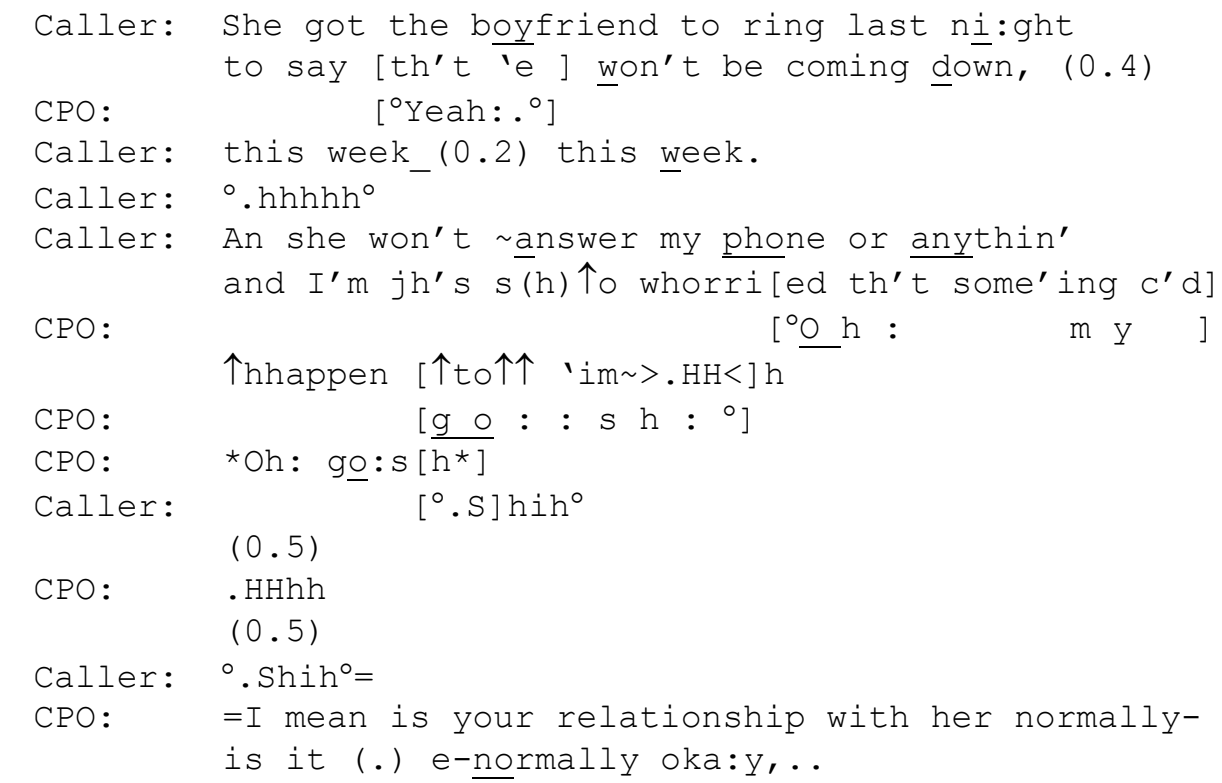


The former are typically used when a caller is so upset that they are unable to speak adequately due to crying, urgency or panic (see also Shaw and Kitzinger, 2013). The latter are significant given the potential issues raised by the callers which may include reported abuse. An explicit emotive reaction to the abuse or sympathy for the victim or reporter is noted as being unusual. Rather, such reports are typically met with an institutionally driven action of evidence gathering to gain further understanding of the problem. However, when crying is heard receipts that express sympathy or empathy are frequent, which suggests a more 'personal response' (p.102).

A related finding is found in calls by adults to a neurological disease specific helpline (Bloch and Antaki, 2018), where there may be resistance from the call-taker to callers emotion displays, particularly as displays of empathy can be the first steps in 'a movement from distance to intimacy' (Jefferson, 1988: 428). This resistance, revealed for example, that by more clearly acknowledging/receipting the physical element of a problem rather than emotional elements of a problem may well reflect the institutional boundaries of what support and help can and cannot be offered. The subtleties of managing emotion are further explored by Shaw \& Kitzinger's home birth helpline work (2013) who examine how the call-taker negotiates the tension between managing the caller's distress about her scheduled hospital labour (the 'presenting problem'), while also encouraging her to arrange a home birth (the 'problem solution'). Of note here is the way in which the call taker makes a rapid move from the end of the problem presentation to a 'solution-type' response, minimising the more commonly seen step-wise sequence from troubles-talk to advice/information/support via the use of information soliciting questions.

Stommel \& Te Molder, (2018) also address empathy by addressing how displays of empathy may serve crucial institutional goals in advice-giving interaction, specifically how empathy can provide a bridge between a caller's problem presentation and the call-taker's advice. Through their examination of calls to an alcohol and drugs information line they identify three ways in which empathic responses may work: a) endorsing the caller's feelings, b) playing down the feelings (disaffiliative), or c) implying the feelings are counterproductive (understandable but not beneficial).

Finally, in addition to expressions of empathy we identified one paper that addresses the specifics of crying-in-interaction (Hepburn 2004). The paper identifies and demonstrates how different features of crying can be transcribed, and therefore treated as a topic for analysis in its own right. Hepburn shows that crying (like laughter) deserves serious consideration in terms of call-taker response. Indeed, she states "...the detailed transcription of the sounds that make up crying warrants more than the simple noting of its occurrence in transcripts" (p286).

\section{Advice giving}

At least eleven of the papers reviewed here deal directly with what is called 'advice', a common response to troubles telling (Jefferson \& Lee, 1992) and defined as a sequence 'in which an interactant describes, recommends, or otherwise forwards a . . course of action' (Heritage and Sefi,1992: 368). This recognises that in institutional settings where help is sought and delivered, the overall activity relates to problem solving rather than troubles telling, the opposite is the case in a troubles-telling environment (Jefferson and Lee, 1981).

Evidence reviewed for this paper identifies a key area of potential conflict and that is callers asking call-takers to provide medical advice when they are prohibited from doing so 
by their service guidelines. This very practical problem arises for two key reasons: a) the boundaries of professional practice and the mission of the helpline prevents the giving of medical advice; and relatedly, b) the limits of a one-off telephone-based contact means that both practically and epistemically the call takers hands are tied. That is, they do not have access to prior records/visits and cannot view and survey the patient's body in a way that is possible in a face-to-face encounter. They simply are not in a position to offer specific medical advice.

Butler et al., (2009) examine how nurses as call takers on a Child Health Line manage this tension between a caller expectation for medical advice and an institutional mandate to avoid providing such advice. Through their analysis the authors reveal three ways in which call takers manage patient expectation regarding the delivery of medical advice: 1) establishing boundaries of expertise and being explicit about what they can and cannot offer (see Extract 8) 2) privileging parental authority and thus downgrading their own authority and 3) drawing on expertise to re-specify a medical problem, for example, by converting it into a parenting or child-developmental issue.

Extract 8: Establishing boundaries

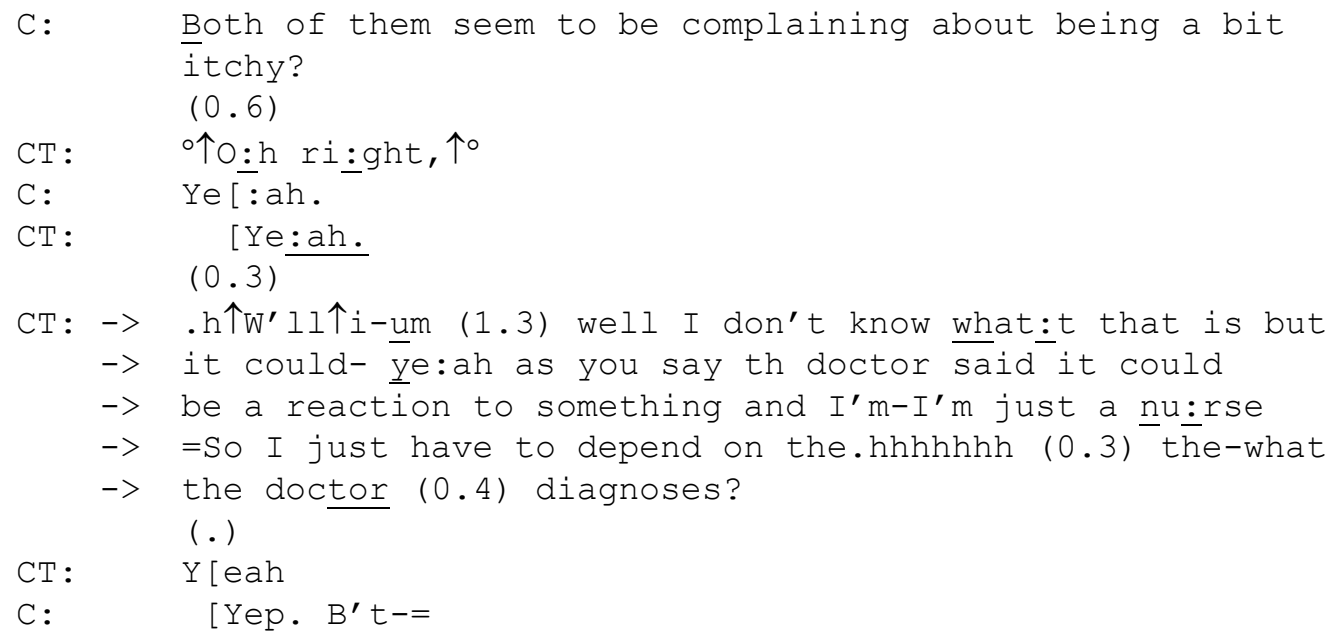

[Source: Butler et al, 2009: p821]

Such a tension is compounded by the fact that the distinction between medical and nonmedical advice is far from clear as well as the fact that the calls to this service typically relate to a third party (the child) who cannot be physically examined or questioned. One device used in this potentially difficult situation is the use of non-personalised information as a normalising device (see also, Bloch and Antaki, 2018, for a similar finding). In this way problems relating to the individual in question are dealt with through reference to the wider population.

Through their exploration of how medical advice is managed the authors raise an important issue regarding the understanding of advice itself and the distinction between the provision of medical advice and medical information or facts (Pilnick, 1999).The latter being non-directive and, assumingly, not something that breaches the guidelines. Thus, one way in which call-takers can meet both caller expectations and institutional requirements is to 
provide a response that can be heard and treated as advice but looks, on paper, to be information.

Also noted are cases where the caller wants something that the call taker cannot provide: e.g. advice which counsellors work to avoid giving directly. They will provide information and will listen but this is quite different from more medically oriented helplines where direct advice is more evident. Again, this presents a challenge to the collective study of helplines because call takers are often mandated to do and are doing different things. Danby et al. (2005) make a useful statement about the Kids Helpline: 'instead of a format of 'problem identification - advice giving'. What we see in these calls is a format of 'talking about problems - listening to that talk' or even just 'talking - listening', (p.148).

As well what does and does not constitute advice we see evidence of advice construction and negotiation. Call analysis of a Poison Information Centre (Landqvist, 2005) shows how advice placement and format varies according to the estimated risk. For example, a higher risk estimate by the call-taker is shown to demand more commitment to act and to provide more immediate advice. This provides further evidence that callers contribute actively in the (co)-construction of advice and specifically what kind of advice may be warranted.

It is also clear that not all helplines aim to provide advice. Butler et al., (2015) explore what happens when a service prioritises emotional reciprocity by focussing on the problem teller and their experiences rather than attempting to solve the problem or tell the caller what to do. The authors describe a number of methods through which call takers accomplish a focus on the 'teller'. For example, they use questions that minimise the normative and asymmetrical dimensions of advice and design their turns at talk in ways that emphasise the relevance and importance of the callers own experiences. Of interest here is the fact that restrictions against 'giving advice' on the Kids Helpline arise from what call takers do as counsellors (child empowerment) rather than a more technical restriction relating to health line professional boundaries (Butler et al., 2009).

Further helpline work shows how advice is shaped to meet the caller's experiences and knowledge in relation to their own epistemic authority. This involves call takers delivering advice in a way that is highly contingent upon the caller's accounts of their experience, and understandings (Butler, Potter, Danby, Emmison, \& Hepburn, 2010).

Whilst much of the work reviewed addresses the design of advice, one paper directs attention to the advice recipient rather than advice-giver, particularly how advice recipients accept or reject advice (Pudlinksi, 2002). Callers are shown to reject advice by reporting how they have already considered what was asked for, or by stating additional conditions, known only to themselves, that prevent the advice from succeeding. This would suggest that rejecting advice is not a simple matter. Indeed, some callers have been shown to pre-empt certain types of advice during the problem presentation itself by stating how they have already tried to resolve their troubles in order to avoid being advised to do something they have in fact already done (Bloch \& Antaki, 2018).

Finally, with reference to placement, in certain circumstances advice is shown to occur very early on in the call (Shaw \& Kitzinger, 2013). Analysis also reveals the shift from rejection to acceptance over the course of the interaction.

\section{Closings}

The accomplishment of everyday telephone conversation closings have received prior attention (Antaki, 2002; Schegloff \& Sacks, 1973). For this review we have identified two papers that address closings on helplines. One considers the relationship between caller satisfaction and closings (Woods et al., 2015). Such satisfaction work is shown to be subtle 
and sophisticated, with moves towards closure beginning with upgraded forms of appreciation observed in the majority of calls. Of particular note is the fact that due to the complexity of the problems, and the limited epistemic and physical access to the caller and their concern call takers are not always able to fully meet caller expectations. This in turn can lead to downgraded expressions of satisfaction with the information or advice given which can themselves pose difficulties for the participants in reaching termination. Indeed, as shown in Extract 8 below, the work shows how call-takers may hold off closing and instead pursue some display of caller satisfaction to ensure their expectations have (at least in part) been met.

\section{Extract 9: Caller Dissatisfaction}

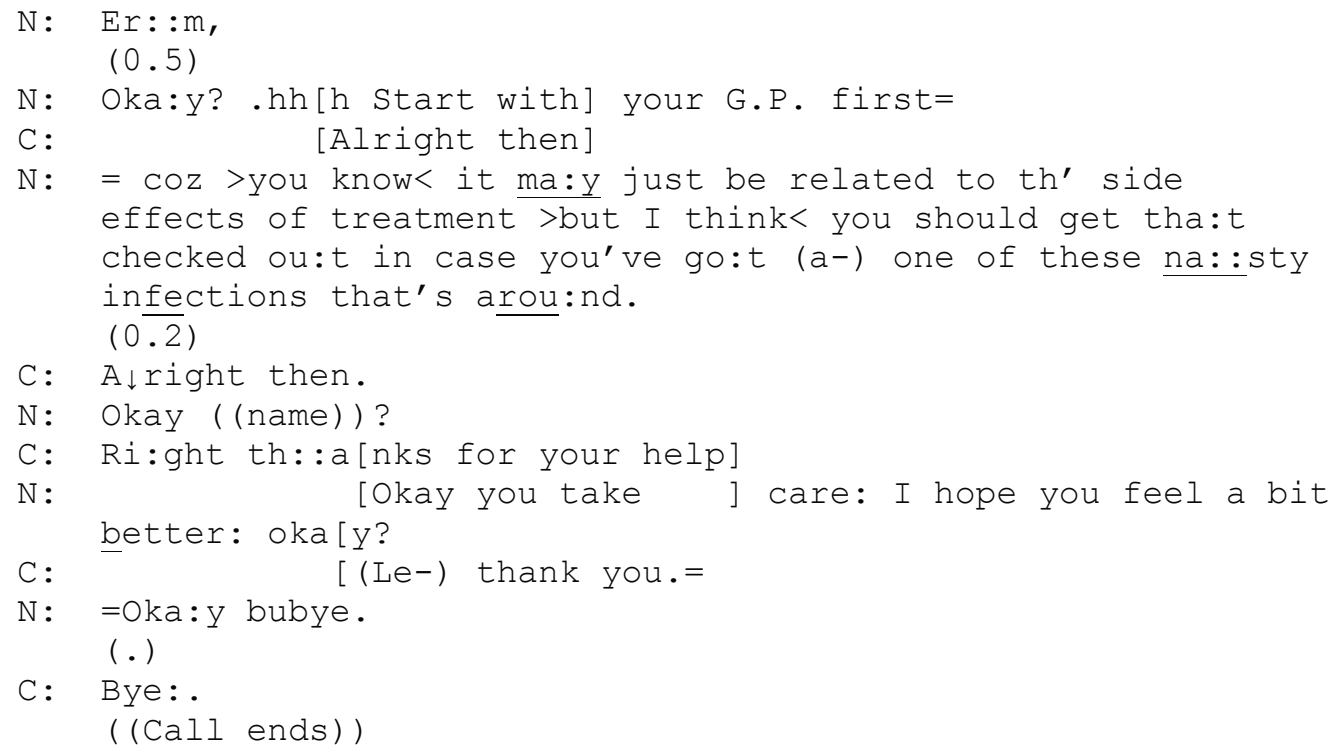

[Source: Woods et al, 2015: p949]

Stommel and te Molder (2015) also focus on closings. Their work, on an alcohol and drugs helpline, deals with both telephone and an online text based chat service provided by trained counsellors. They analyze chat session closings with the aim of understanding how chat counselling works potentially differently from spoken forms of counselling.

\section{Authenticity/motive/pranks calls}

A recurring question in counselling helplines (chat and phone) is whether the help seeker is genuine. A practice seen in a number of calls to the Kids Helpline (Weatherall, Danby, Osvaldsson, Cromdal, \& Emmison, 2016) was the setting up of provocative traps to get the call-taker to say something that was construed as taboo, that is, to 'prank' the call-taker.

Emmison \& Danby (2007) examine interactional strategies that call takers employ to establish the authenticity of a call, including subtle response strategies (such as reversing the direction of questioning when the answer expected by the potential prank caller is likely to include sexual or scatological words) that do not directly challenge the caller and thus avoid the risk of upsetting a genuine caller. So called prank calls are hard to define but are deemed inauthentic in that they are not designed to solicit help or advice. Whilst some calls may 
prove to be obvious pranks, other 'testing calls' may represent a young person's first attempt to investigate help and how it might be provided.

\section{Identity}

Whilst the majority of papers consider issues germane to the institutional or professional concerns of callers and call-takers, a small number make use of data to identify specific practices independent or less central to the helpline setting. The treatment of identity and gender, for example, is perhaps less explicit in its helpline relevance although membership categorisation may well be of significance in how, for example, participants display their stance towards a central issue. In their examination of gender construction in interaction, Kitzinger and Rickford (2007), for example, show how a call-taker's change in reference from the caller's 'partner' to 'bloke', is done in pursuit of an institutional goal: to advise the caller to take her partner, as an advocate, to a pending health related consultation.

As well as addressing the construction of a caller's identity, te Molder (2005) makes an important comment that the call-taker also does work to confirm her own identity as 'a help giver'. Analysis of one call to a health helpline in the Netherlands shows how the caller, through reversing conversational roles and by attempting to explore non-institutional private or personal issues, redefines the implicit rules of the helpline itself. The caller here is shown to be depicting herself as ordinary and normal rather than someone who is seeking help. Of additional interest here is the 'identity-relationship' between caller and call-taker, something that is managed in and through the participants' talk rather than re-defined or permanent.

\section{Assessments}

The final theme identified in the reviewed literature relates to call-taker assessments. Shaw \& Kitzinger (2012) analyse positive assessments, in the form of compliments, across 80 calls to a helpline for women seeking a home birth. The findings contribute to an understanding of compliments and compliment responses in a particular institutional environment. It challenges previous assumptions about the formulaic nature of compliments. Rather, participants employ a far wider range of syntactic and semantic resources in their design of compliments than previously reported.

Finally, in what may be considered a surprising feature of helpline calls, Pudlinksi (2008) examines call-taker responses to caller good news. The sequences presented include reports on good news tied to a current or ongoing problem. Call takers are shown to use four different methods, such as positive assessments and statements of agreement to a planned action, to endorse good news and encourage actions implied within the report. Across all four methods, encouragement allows call-takers to affiliate with the caller, display understanding of the caller's news, and keep the good news topical.

\section{The future of CA and helpline research}

This review has addressed telephone helpline interactions concerning physical or mental health, illness or wellbeing. A number of studies show how talk is organised with reference to helplines, in contrast to other medical/help based interactions, whilst others use the helpline data as a vehicle to understand wider practices irrespective of the helpline context (e.g. seeking and receiving help, or offering assessments). A small number address additional, but no less relevant, practices such as identity management. 
The health-related helpline field of inquiry, together with studies of help and support seeking and provision through different formats, such as online chat, is slowly maturing. To date the majority of papers have centred on the accomplishment of advice in terms of how it is sought, how it is provided and how it might be resisted. Additional work on problem or concern presentations, empathy, emotions and assessments reflect the range of actions accomplished by participants. Two previous collections on help (Baker et al., 2005; Edwards, 2007) have promoted the study of telephone helpline-interactions but the field remains open for a more systematic investigation of the organisation of health related helpline calls.

\section{On the application of helpline analysis to real world problems}

Several of the papers we have reviewed make reference to how findings might impact on the day-to-day work of health helplines. The certainty of any recommendations or considerations for application vary considerably. Woods et al. (2015) for example have an explicit section on practice implications: aiming to improve 'the effectiveness of call-handling' (p.951). Butler et al. (2009) state that their findings have implications for policy, training and practice in relation to telephone helplines. Similarly, Shaw and Kitzinger (2013) end their work with implications for developing effective practice for services. The latter show how the findings from their research on the Home Birth helpline have been applied to training and practice. There are also statements of the intention to use findings in future training for call-takers (Kitzinger and Rickford, 2007).

The notion of a more formal applied conversation analysis, and its various forms, has been explored with clarity in previous work (Antaki, 2011). Here we consider interventionist applied $C A$, in which researchers, through the use of analytical findings, address specific problems faced by specific institutions, and with specific outcomes in mind. Some papers preface their analysis with a very explicit institutional problem or concern. In their study of crying receipts for example, Hepburn \& Potter (2007) begin their paper by informing the reader about what they had been told by the helpline: that dealing with callers who were crying was one of the most difficult tasks for the Child Protection Officers as call takers. How to manage distress as one of the most pressing concerns for many helpline staff begins another paper (Shaw \& Kitzinger, 2013), whilst Pudlinski (2002) begins his work with a 'common dilemma' faced by clients in a variety of advice-giving contexts. As such, addressing real world problems appears, at least in part, to be one motivator for helpline call analysis.

We have identified three clear examples of applied CA in the field of health helplines. These provide a detailed description of what they have achieved practically. Kitzinger (2011) describes her experiences of working with three organisations (childbirth helplines), both in groups and with individual call-takers, and how they use her analyses to develop and improve their own work and services. The fact that the call-takers in all three organisations had never recorded or listened to their own calls, reveals an important point regarding the potential challenges of this type of intervention. Equally, Kitzinger makes the critical point that CA is descriptive, not prescriptive: it does not in itself enable us to say that one form of interaction is any better than another. Leydon, Ekberg, Kelly, \& Drew, (2013) developed a workshop based training (available online or to be used in group workshops) to train call handlers how to ask the ethnicity question to increase validity of the data collected and to enhance the progressivity / comfort of the call for callers and call -takers. Finally, Hepburn, Wilkinson, \& Butler (2014) focus on three research themes (a) the giving, receiving, and resisting of advice; (b) the expression of strong emotion, its identification and management, and (c) how helplines' policies and practices shape the interactions between caller and call taker. They encourage practitioners to engage with the detail of their practices so that they can consider 
what they currently do, recognize good practice in different situations, and start to use it as scaffolding to think about how they might do things differently. Through this work they recognize the existing skills of the call-takers. They also incorporate issues related to procedural matters into feedback and training.

Who is the main focus: caller, call-taker or both?

In some papers there appears to be an explicit recognition that call-takers have received more attention than callers (see for example Pudlinski, 2002). Subsequent work has perhaps redressed this imbalance, but it is clear that the category of 'call-taker' is far from homogenous. Call-takers may be highly trained and experienced professionals (Bloch \& Antaki, 2018; Landqvist, 2005) or non-professional peers who are no less credible/knowledgeable and whom bring a different skill set. Peers as call takers raises an interesting issue regarding the ways in which empathy and sympathy can be expressed. As Pudlinkski (2005) comments: '...doing empathy and sympathy will likely be less straightforward in asymmetrical settings, as impulses towards diagnosis and problem solving will likely create more intricate dilemmatic strategies for doing social support.' (p.286). Understanding how caller and call-taker epistemics are bought into play is a key issue here in terms of how help and support are organised.

\section{What is needed and where this field of inquiry needs to go}

It is inevitable that new forms of technology will be employed in the service of help and support. At present there remain three predominant formats: face-to-face, telephone/voice and online text-based support (both synchronous and asynchronous). The relationship between these formats has been explored in part (Harris et al., 2012; Stommel \& te Molder, 2015) but more work is needed to consider how participants manage help and advice practices across different platforms.

There may also be value in considering differences across callers. Hepburn (2005), for example, identifies a number of areas for future enquiry with reference to children. Do they in general provide more or less information than adults? Is more or less information sought from call-takers? We also note that callers can vary in terms of epistemic authority. Many calls come directly from people seeking help or advice regarding their own physical and/or psychological wellbeing, but we also observe calls from partners, parents, concerned friends and occasionally professionals seeking specialist advice. How this status is demonstrated and responded to may yield useful findings.

Many of the services we have considered in this review provide support and training for their call-takers, presumably carrying perceptions of what may be loosely termed 'good' and 'bad' calls. However, little is known about the interactional dynamics that lead to 'success' or 'failure' of these telephone-mediated encounters (or indeed what success or failure mean in this context) and about how these challenges affect the services provided during the calls.

Helplines is a useful descriptive gloss for a range of services and this range is extremely diverse. There may well be value in considering how these services can be most usefully categorized. A taxonomy of helplines based on the types of interactive work the participants are mandated to undertake and accomplish (e.g. signposting, counselling, emotional support, onward referral, intervention etc.) may provide a fruitful framework to help understand the similarities and differences between the range of health-related helplines. 
This may usefully include discussion regarding the relationship between helplines and other remote advice/support services including text/chat-based advice as well as telehealth.

With reference to complexity, many callers contact helplines for both information/advice and psychosocial support and many request these during the same call. Quite often these multiple concerns will not emerge until much later in a call, suggesting a need to actively agenda-set to ensure the full spectrum of caller concerns are elicited and managed. Certainly, work in other settings including primary care consultations in North America and the UK have shown that setting the agenda early is a realistic practice and one that can limit the possibility of unmet concerns. This practice in the helpline setting is not well understood and requires further investigation.

\section{References}

Antaki, C. (2002). "Lovely": turn-initial high-grade assessments in telephone closings. Discourse Studies, 4, 5-23. doi.10.1177/14614456020040010101

Baker, C., Emmison, M., \& Firth, A. (2005). Calling for Help. (C. Baker, M. Emmison, \& A. Firth, Eds.). Amterdam: John Benjamins.

Bloch, S., \& Antaki, C. (2018). The Pivot Point between Problem Presentation and Advice in a Health Helpline Service. Applied Linguistics, 2018, 1-19. doi.10.1093/applin/amy014

Butler, C., Danby, S., \& Emmison, M. (2015). Avoiding giving advice in telephone counselling for children and young people. In F. H. . Chevalier \& J. Moore (Eds.), Producing and Managing Restricted Activities: Avoidance and withholding in institutional interaction (pp. 83-114). John Benjamins.

Butler, C., Danby, S., Emmison, M., \& Thorpe, K. (2009). Managing medical advice seeking in calls to Child Health Line. Sociology of Health and Illness. doi.10.1111/j.14679566.2009.01179.x

Butler, C. W., Potter, J., Danby, S., Emmison, M., \& Hepburn, A. (2010). Advice-implicative interrogatives: Building "client-centered" support in a children's helpline. Social Psychology Quarterly, 73, 265-287. doi.10.1177/0190272510379838

Danby, S., Baker, C., \& Emmison, M. (2005). Four observations on openings in calls to Kids Help Line. In C. Baker, M. Emmison, \& A. Firth (Eds.), Calling for help : language and social interaction in telephone helplines (pp. 133-151). Amstersdam: John Benjamins.

Drew, P., \& Heritage, J. (1992). Analyzing talk at work: an introduction. In P. Drew \& J. Heritage (Eds.), Talk at Work (pp. 3-65). Cambridge: Cambridge University Press.

Edwards, D. (2007). Introduction. Research on Language and Social Interaction, 40, 1-7. doi.10.1080/08351810701331190

Emmison, M., \& Danby, S. (2007). Who's the friend in the background?: Interactional strategies in determining authenticity in calls to a national children's helpline. Australian Review of Applied Linguistics, 30(3). Retrieved from https://benjamins.com/catalog/aral.30.3.02emm/fulltext

Firth, A., Emmison, M., \& Baker, C. (2005). Calling for Help: An Introduction. In C. Baker, M. Emmison, \& A. Firth (Eds.), Calling for Help. Amsterdam: John Benjamins.

Harris, J., Danby, S., Butler, C. W., \& Emmison, M. (2012). Extending client-centered support: Counselors' proposals to shift from e-mail to telephone counseling. Text and Talk, 32, 21-37. doi/10.1515/text-2012-0002

Hepburn, A. (2005). "You're Not Takin" Me Seriously": Ethics and Asymmetry in Calls to a Child Protection Helpline.” Journal of Constructivist Psychology, 18, 253-274. doi.10.1080/10720530590948836

Hepburn, A., \& Potter, J. (2007). Crying Receipts: Time, Empathy, and Institutional Practice. Research on Language and Social Interaction, 40, 89-116. 
doi.10.1080/08351810701331299

Hepburn, A., Wilkinson, S., \& Butler, C. W. (2014). Intervening With Conversation Analysis in Telephone Helpline Services: Strategies to Improve Effectiveness. Research on Language and Social Interaction, 47, 239-254. doi.10.1080/08351813.2014.925661

Heritage, J., \& Sefi, S. (1992). Heritage, J. and Sefi, S. Dilemmas of Advice: aspects of the delivery and reception of advice in interactions between health visitors and first-time mothers. In P. Drew \& J. Heritage (Eds.), Talk at Work (pp. 359-417). Cambridge: Cambridge University Press.

Hopper, R. (1993). Telephone Conversation. Bloomington: Indiana Universty Press.

Jefferson, G. (1988). On the Sequential Organization of Troubles-Talk in Ordinary Conversation. Social Problems, 35, 418-441. doi.10.2307/800595

Jefferson, G., \& Lee, J. R. E. (1992). The rejection of advice: managing the problematic conveergence of a "troubles-telling" and a "service encounter." In P. Drew \& J. Heritage (Eds.), Talk at Work (pp. 521-548). Cambridge: Cambridge University Press.

Kitzinger, C. (2011). Working with Childbirth Helplines: the contributions and Limitations of Conversation Analysis. In Applied Conversation Analysis. doi.10.1246/c1.140020

Kitzinger, C., \& Rickford, R. (2007). Becoming a 'Bloke': The Construction of Gender in Interaction. Feminism \& Psychology, 17, 214-223. doi.10.1177/0959353507076554

Landqvist, H. (2005). Constructing and negotiating advice in calls to a poison information centre. In C. Baker, M. Emmison, \& A. Firth (Eds.), Calling for help : language and social interaction in telephone helplines (pp. 207-234). Amsterdam: John Benjamins.

Leydon, G. M., Ekberg, K., \& Drew, P. (2013). “ How can I help?” Nurse call openings on a cancer helpline and implications for call progressivity. Patient Education and Counseling, 92, 23-30. doi.10.1016/j.pec.2013.02.007

Leydon, G. M., Ekberg, K., Kelly, M., \& Drew, P. (2013). Improving ethnic monitoring for telephone-based healthcare: a conversation analytic study. BMJ Open, 3(6), e002676. doi.10.1136/bmjopen-2013-002676

Maynard, D. W., \& Heritage, J. (2005). Conversation analysis, doctor-patient interaction and medical communication. Medical Education, 39, 428-435. doi.10.1111/j.13652929.2005.02111.x

Parry, R. H., \& Land, V. (2013). Systematically reviewing and synthesizing evidence from conversation analytic and related discursive research to inform healthcare communication practice and policy: an illustrated guide. BMC Medical Research Methodology, 13, 69. doi.10.1186/1471-2288-13-69

Pilnick, A. (1999). Patient counselling by pharmacists: Advice, Information or Instruction? Sociological Quarterly, 40, 613-622.

Potter, J., \& Hepburn, A. (2003). "I'm a Bit Concerned" - Early Actions and Psychological Constructions in a Child Protection Helpline. Research on Language and Social Interaction, 36, 197-240. doi.10.1207/S15327973RLSI3603_01

Pudlinksi, C. (2002). Accepting and rejecting advice as competent peers: caller dilemmas on a warm line. Discourse Studies, 4, 481-500.

Pudlinksi, C. (2005). Doing empathy and sympathy: caring responses to troubles tellings on a peer support line. Discourse Studies, 7, 267-288.

Pudlinksi, C. (2008). Encouraging responses to good news on a peer support line. Discourse Studies, 10, 795-812.

Robinson, J. D. (2003). An Interactional Structure of Medical Activities During Acute Visits and Its Implications for Patients' Participation. Health Communication, 15, 27-59. doi.10.1207/S15327027HC1501_2

Robinson, J. D., \& Heritage, J. (2005). The structure of patients' presenting concerns: the completion relevance of current symptoms. Social Science \& Medicine, 61, 481-493. 
doi.10.1016/j.socscimed .2004.12.004

Royal College of Nursing. (2006). Telephone advice lines for people with long term conditions: Guidance for nursing practitioners. London.

Ruusuvuori, J. (2007). Managing affect: integration of empathy and problem-solving in health care encounters. Discourse Studies, 9, 597-622. doi.10.1177/1461445607081269

Sacks, H. (1967). The Search for Help: No One to Turn. In E. Shneidman (Ed.), Essays in Self Destruction (pp. 203-223). New York: Science House Inc.

Sacks, H. (1992). Lectures on Conversation Vols I \& II. (G. Jefferson, Ed.). Oxford: Basil Blackwell.

Schegloff, E. (1979). Identification and Recognition in Telephone Conversation Openings. In G. Psathas (Ed.), Everyday Language: Studies in Ethnomethodology (pp. 23-78). New York: Irvington Publishers, Inc.

Schegloff, E. (1986). The routine as achievement. Human Studies, 9, 111-151.

Schegloff, E. A. (1968). Sequencing in Conversational Openings. American Anthropologist, 70, 1075-1095.

Schegloff, E. A., \& Sacks, H. (1973). Opening up Closings. Semiotica, 8(4).

Shaw, R., \& Kitzinger, C. (2012). Compliments on a Home Birth Helpline. Research on

Language and Social Interaction, 45, 213-244. doi.10.1080/08351813.2012.699251

Shaw, R., \& Kitzinger, C. (2013). Managing Distress, Effecting Empowerment: A Conversation Analytic Case Study of a Call to the Home Birth Helpline. International Review of Social Research, 3, 7-28. doi.10.1515/irsr-2013-0008

Stommel, W., \& Molder, H. te. (2018). Empathically designed responses as a gateway to advice in Dutch counseling calls. Discourse Studies, 20, 523-543. doi.10.1177/1461445618754436

Stommel, W., \& te Molder, H. (2015). Counseling Online and Over the Phone: When Preclosing Questions Fail as a Closing Device. Research on Language and Social Interaction, 48, 281-300. doi.10.1080/08351813.2015.1058605

Taylor, D., \& Bury, M. (2007). Chronic illness, expert patients and care transition. Sociology of Health \& Illness, 29, 27-45. doi.10.1111/j.1467-9566.2007.00516.x

Te Molder, H. (2005). I just want to hear somebody right now? Managing identities on a telephone helpline. In C. Baker, M. Emmison, \& A. Firth (Eds.), Calling for help : language and social interaction in telephone helplines (pp. 154-173). Amstersdam: John Benjamins.

Weatherall, A., Danby, S., Osvaldsson, K., Cromdal, J., \& Emmison, M. (2016). Pranking in children's helpline calls. Australian Journal of Linguistics, 36, 224-228. doi.10.1080/07268602.2015.1121532

Whalen, M. R., \& Zimmerman, D. H. (1987). Sequential and Institutional Contexts in Calls for Help. Social Psychology Quarterly, 50, 172-185. doi.10.2307/2786750

Woods, C. J., Drew, P., \& Leydon, G. M. (2015). Closing calls to a cancer helpline: Expressions of caller satisfaction. Patient Education and Counseling, 98, 943-953. doi. 10.1016/j.pec .2015.04.015 